\title{
A genome scan for quantitative trait loci affecting milk somatic cell score in Israeli and Italian Holstein cows by means of selective DNA pooling with single- and multiple-marker mapping
}

\author{
R. Tal-Stein, ${ }^{* 1}$ L. Fontanesi, $\dagger^{1}$ M. Dolezal, $\ddagger$ E. Scotti, $†$ A. Bagnato,§ V. Russo, $†$ F. Canavesi,\# A. Friedmann, ${ }^{*}$ \\ M. Soller, ${ }^{*}$ and E. Lipkin ${ }^{* 2}$ \\ *Department of Genetics, The Hebrew University of Jerusalem, 91904 Jerusalem, Israel \\ †Dipartimento di Protezione e Valorizzazione Agroalimentare, Sezione di Allevamenti Zootecnici, Università di Bologna, 42100 Reggio Emilia, Italy \\ ‡Institut für Populationsgenetik, University of Veterinary Medicine Vienna, 1210 Vienna, Austria \\ $\S$ Department of Veterinary Sciences and Technologies for Food Safety, Università degli Studi di Milano, 20133 Milano, Italy \\ \#Associazione Nazionale Allevatori Frisona Italiana (ANAFI), 26100 Cremona, Italy
}

\begin{abstract}
Mastitis is an important and common dairy cattle disease affecting milk yield, quality, and consumer safety as well as cheese yields and quality. Animal welfare and residues of the antibiotics used to treat mastitis cause public concern. Considerable genetic variation may allow selection for increased resistance to mastitis. Because of high genetic correlation to milk somatic cell score (SCS), SCS can serve as a surrogate trait for mastitis resistance. The present study intended to identify quantitative trait loci (QTL) affecting SCS in Israeli and Italian Holstein dairy cattle (IsH and ItH, respectively), using selective DNA pooling with single and multiple marker mapping. Milk samples of 4,788 daughters of $6 \mathrm{IsH}$ and $7 \mathrm{ItH}$ sires were used to construct sire-family high- and low-tail pools, which were genotyped at 123 ( IsH) and 133 (ItH) microsatellite markers. Shadow correction was used to obtain pool allele frequency estimates. Frequency difference between the tails and empirical standard error of $\mathrm{D}, \mathrm{SE}(\mathrm{D})$, were used to obtain $P$-values. All markers significant by single marker mapping were also significant by multiple marker mapping, but not vice versa. Combining both populations, 22 QTL on 21 chromosomes were identified; all corresponded to previous reports in the literature. Confidence intervals were set by chi-squared drop method. Heterozygosity of QTL was estimated at $44.2 \%$. Allele substitution effects ranged from 1,782 to 4,930 cells $/ \mathrm{mL}$ in estimated breeding value somatic cell count units. Most $(80 \%)$ of the observed variation in estimated breeding value somatic cell score could be explained by the QTL identified under the stringent criteria. The results found here can be used as a ba-
\end{abstract}

Received March 11, 2010.

Accepted June 25, 2010.

${ }^{1} \mathrm{R}$. Tal-Stein and L. Fontanesi contributed equally to this study.

${ }^{2}$ Corresponding author: lipkin@vms.huji.ac.il sis for further genome-wide association studies for the same trait.

Key words: dairy cattle, genome scan, quantitative trait loci, somatic cell score

\section{INTRODUCTION}

Clinical mastitis (CM) negatively affects animal welfare (Kemp et al., 2008), animal production, and the quality of the milk produced (reviewed in Heringstad et al., 2000; Seegers et al., 2003). Concern over $\mathrm{CM}$ is exacerbated by the positive genetic correlation between milk yield (MY) and CM, which indicates that selection for MY may have caused an increase in the incidence of CM (reviewed in Rupp and Boichard, 2003). In addition to the direct economic costs, the increase in culling rate because of $\mathrm{CM}$ reduces the reproductive potential of the dairy herd, bringing it dangerously close to the minimum needed to maintain herd numbers. Furthermore, CM is caused by a wide variety of opportunistic microorganisms; hence, susceptibility may reflect general immune status. This is supported by empirical selection experiments showing that selection for increased MY increases all health costs, not only those related to mastitis (Hansen et al., 1979; Dunklee et al., 1994). Concern regarding effects of selection for $\mathrm{MY}$ on $\mathrm{CM}$ incidence has led to the adoption of selection programs aimed at reducing or at least controlling the incidence of CM by all leading dairy cattle breeding organizations. These programs are based on direct assessment of CM in the Scandinavian countries (reviewed in Heringstad et al., 2000) or on the use of milk SCS as a surrogate marker in most other countries (e.g., Schutz, 1994). These programs appear to have been successful in arresting and even reversing the increase in SCS in the target populations. In Israel, for example, the genetic trend for SCS in Holstein cattle was positive (unfavorable) until 1993 and negative (favorable) thereafter (Weller and Ezra, 
2004); the same is true for US Holsteins, where the trend changed in 2001 (USDA, 2008).

Selection against mastitis is generally implemented as part of a total merit index that treats the correlated genetic effects as uniform across the genome. This need not be the case. For example, although there is a moderately high negative genetic correlation between MY and protein percentage, it appears that some QTL exclusively affect either protein percentage or MY and others affect both traits (Bagnato et al., 2008; Lipkin et al., 2008). Because the genetic correlation of MY and SCS and CM is only about 0.30 (see Rupp and Boichard, 2003), loci may exist that affect only MY or only SCS and CM. Marker-assisted selection targeted to particular classes of loci rather than globally may be more effective than simple index selection. As a step to exploring these possibilities, a genome-wide mapping experiment for SCS was implemented in the Israeli and Italian Holstein (IsH and ItH, respectively) dairy cattle populations using selective DNA pooling with single-marker mapping (SMM) as implemented in previous studies (Lipkin et al., 1998, 2008; Mosig et al., 2001; Bagnato et al., 2008) and also with multiplemarker mapping (MMM) as proposed by Dolezal et al. (2008).

\section{MATERIALS AND METHODS}

\section{SCS}

Because the actual distribution of SCC is highly asymmetrical and skewed to the right, SCC are commonly converted into SCS using the widely accepted expression of Ali and Shook (1980):

$$
\mathrm{SCS}=\log _{2}(\mathrm{SCC} / 100)+3 .
$$

Somatic cell count is given in cells per microliter. Somatic cell score distributes in a much more symmetrical fashion than SCC.

In Israel, reported SCS EBV are expressed as deviation from the mean SCS EBV in 1995, which was equal to 2.94. For Italy, SCS EBV are reported as SCS index (SCSI), which is equal to $3.33(2.9-\mathrm{SCS})+4$; this is done so that high index values will correspond to low SCS (i.e., high index values will be favorable). Therefore, to enable comparison of Israeli and Italian data, 2.94 was added to the reported SCS EBV for Israel to give absolute SCS, whereas Italian SCSI values were reconverted to absolute SCS using the following expression: $\mathrm{SCS}=2.9-(\mathrm{SCSI}-4) / 3.33$.

Sampling and Pooling. Daughter EBV for SCS were obtained for all daughters of 6 full service IsH AI sires, each with at least 1,600 milking daughters, and for 7 full service ItH AI sires, each with at least 3,200 milking daughters. As suggested by Dolezal (2007), raw EBV (rEBV) for the IsH cows was corrected for the dam effect by subtracting half of the dam EBV from the daughter EBV. The resultant value was termed corrected EBV (cEBV). Correction for dam EBV will necessarily reduce the variation among the daughters. However, the remaining variation should be more directly attributable to the effect of the sire alleles. Thus, it is anticipated that effective selection for cEBV will be greater than that for rEBV.

For the ItH cows, EBV for SCS were estimated solely for the daughters of the $7 \mathrm{AI}$ sires participating in this study; dam EBV were not available. Consequently, rEBV were used in this population. Daughters of each sire were ranked according to cEBV SCS (Israel) or rEBV SCS (Italy), and highest and lowest ranking daughters were chosen for inclusion in the high and low pools for each sire, respectively. Taking into account that some daughters in the ranked sire lists would not be in milk at the time of sampling, 260 daughters were selected for sampling from each tail to provide 200 effectively sampled daughters for each tail. For statistical purposes, the sampled daughters in each tail of each sire were divided at random among 2 high and 2 low replicate subpools of up to 100 daughters each. Each subpool was made up in 2 duplicates prepared independently. Thus, there were 4 subpools per tail (2 replicates $\times 2$ duplicates per replicate) for a total of 8 subpools. In Israel, initially the first duplicate of each replicate was genotyped. The second duplicate was genotyped under the following circumstances: the marker was significant or approaching significance, the first genotype had poor quality, the distribution of allele frequencies did not match the sire genotype at the marker, a discrepancy was found between the 2 replicates of the same tail, or a discrepancy was found between sire results in adjacent markers. In Italy, initially all 8 subpools were genotyped and subsequently regenotyped if the first genotype had poor quality.

Markers. After testing a large set of microsatellite markers for amplification efficiency, genotyping clarity, and heterozygosity, the IsH and ItH pools were genotyped for 123 and 133 microsatellite markers, respectively, distributed over the 29 bovine autosomes. Of these, 68 markers were genotyped in both populations whereas 56 and 65 markers were genotyped only in IsH or ItH, respectively, for a total of 189 markers.

\section{Sample Preparation and Genotyping}

Cells (IsH, $\mathrm{n}=25,000 ;$ ItH, $\mathrm{n}=20,000$ ) were taken from each daughter to construct each of the replicate and duplicate subpools to which the daughter in ques- 
tion was allocated. Details of the genotyping procedure differed somewhat between Israel and Italy and are presented as Appendix I.

\section{Estimation of Sire-Marker Allele Frequencies in the Pools}

Sire-marker allele frequencies in the pools were estimated by densitometric genotyping with correction for "shadow bands" as described (Lipkin et al., 1998). This resulted in 8 pool frequencies for each sire-marker combination, as follows. For each marker, high and low pools were denoted $\mathrm{H}$ and $\mathrm{L}$, respectively; the long and short sire alleles by $\mathrm{L}$ and $\mathrm{S}$, respectively; and the 2 replicate subpools by 1 and 2, respectively. Using this notation, HL1, for example, would denote the frequency in the high pool of the long sire allele in replicate subpool 1. Subscripts ij should be appended to each expression to indicate that these are calculated separately for each sire $_{\mathrm{i}} \times$ marker $_{\mathrm{j}}$ combination. For the statistical analyses, when genotypes of replicate subpools were not available, allele frequencies from the corresponding subpools were copied to the missing pool.

\section{Marker-QTL Linkage Tests}

$\boldsymbol{S M}$. Single-marker significance tests were carried out as described (Bagnato et al., 2008; Lipkin et al., 2008). Briefly, a test statistic for the ijth sire $\times$ marker combination was calculated as

$$
\mathrm{Z}_{\mathrm{ij}}=\text { Dtest }_{\mathrm{ij}} / \mathrm{SD}(\text { Dnull }),
$$

where Dtest $_{\mathrm{ij}}=[(\mathrm{HL} 1+\mathrm{HL} 2)-(\mathrm{HS} 1+\mathrm{HS} 2)-(\mathrm{LL} 1$ $+\mathrm{LL} 2)+(\mathrm{LS} 1+\mathrm{LS} 2)] / 4$ is the difference in sire allele frequencies between the high and low daughter pools of the ith sire with respect to the jth marker, averaged over the long and short sire alleles and over the 2 subpools of the same tail. Dnull $l_{\mathrm{ij}}=[(\mathrm{HL} 1-\mathrm{HL} 2)-(\mathrm{HS} 1$ - HS2 $)+($ LL1 - LL2) - (LS1 - LS2)]/4 is the difference in allele frequencies between the 2 subpools of the same tail of the ith sire with respect to the jth marker, averaged over the long and short sire alleles and the high and low pools. Dtest ${ }_{i j}$ and Dnull ${ }_{i j}$ were calculated only for markers for which the sire was heterozygous. Because Dnull $_{\mathrm{ij}}$ is calculated within tails, it has expectation of 0 and thus should distribute as the D under the null hypothesis of no QTL effect. Thus, the standard deviation (SD) of the Dnull $\mathrm{ij}_{\mathrm{ij}}$ values obtained across all markers $\left[\mathrm{SD}\left(\right.\right.$ Dnull $\left.\left._{\mathrm{ij}}\right)\right]$ is an empirical estimate of the standard error of Dtest $\mathrm{ij}_{\mathrm{ij}}$ under the null hypothesis.

To test for validity of the empirical $\mathrm{SD}(\text { Dnull })_{\mathrm{ij}}$, Z under the null hypothesis was calculated as Znull $_{\mathrm{ij}}=$ Dnull $_{\mathrm{ij}} / \mathrm{SD}(\text { Dnull })_{\mathrm{ij}}$ within tails, and the distribution of Znull ${ }_{\mathrm{ij}}$ was tested for deviation from the standard normal distribution using various tests option normal of PROC UNIVARIATE in SAS (SAS Institute, Cary, $\mathrm{NC})$. Validity of the empirical $\mathrm{SD}(\text { Dnull })_{\mathrm{ij}}$ was further determined by a Schweder-Spjøtvoll diagram (Schweder and Spjøtvoll, 1982) in which $\left(1-\mathrm{P}_{\mathrm{ij}}\right)$ values are sorted in ascending order and plotted against rank number with an expected $45^{\circ}$ regression line under the null hypothesis.

Under the null hypothesis, $\mathrm{Z}_{\mathrm{ij}}$ values distribute as a standardized normal variable, and comparison-wise error rate (CWER) $P$-values for the individual siremarker combinations were obtained accordingly. The test statistic $\left(\mathbf{T S}_{\mathbf{j}}\right)$ for the $\mathrm{jth}$ marker was calculated by summing the $\mathrm{Z}_{\mathrm{ij}}{ }^{2}$ across all heterozygous sires:

$$
\mathrm{TS}_{\mathrm{j}}=\Sigma \mathrm{Z}_{\mathrm{ij}}^{2} \text {. }
$$

Under the null hypothesis, $\mathrm{TS}_{\mathrm{j}}$ distributes as chisquared with degrees of freedom (df) equal to $k$, where $\mathrm{k}$ is the number of sires heterozygous for the marker (Weller et al., 1990). The CWER $P$-values for the jth marker were obtained accordingly.

$\boldsymbol{M} \boldsymbol{M} \boldsymbol{M}$. The SMM marker test statistics $\left(\mathrm{TS}_{\mathrm{j}}\right)$ are strongly affected by the number of sires that are heterozygous for a given marker and the QTL status (homozygous or heterozygous) of these sires. Each marker will have its own set of heterozygous sires, and only sires heterozygous at a marker enter the marker test. This causes strong sampling fluctuations in marker $P$-values across a chromosome and hence decreases the accuracy of QTL mapping. This shortcoming is overcome by the interval mapping approach as developed by Wang et al. (2007). However, this procedure requires sire-marker haplotypes, and user-friendly implementation programs are not available. The MMM approach, on the other hand, based on a simple selection index analogy (Dolezal et al., 2008), overcomes this shortcoming without the need for sire-marker haplotype information. Further details of the MMM procedure are given in Appendix II.

Multiple-marker mapping test statistics can be calculated at 1-cM intervals along the entire chromosome from the observed single-sire SMM test statistics, generating a smooth $P$-score map across the chromosome, without the strong fluctuations of SMM. However, Tables 3 and 4 later in the text present $P$-values by SMM and MMM for only the marker locations and not for intermarker locations, even if there was a maximum MMM $P$-value at an intermarker location.

\section{Setting Significance Levels}

Initially, proportion of false positives (PFP; Fernando et al., 2004; previously termed aFDR by Mosig et al., 
2001) and false discovery rate (FDR; Benjamini and Hochberg, 1995) were used to set CWER significance thresholds for declaring significance:

$$
\begin{gathered}
\mathrm{FDR}=\mathrm{n}_{\mathrm{M}} \times \mathrm{P}_{\mathrm{C}} / \mathrm{R}_{\mathrm{C}} \text { and } \\
\mathrm{PFP}=\mathrm{n}_{2 \mathrm{M}} \times \mathrm{P}_{\mathrm{C}} / \mathrm{R}_{\mathrm{C}},
\end{gathered}
$$

where $\mathrm{n}_{\mathrm{M}}$ is the total number of marker tests performed; $\mathrm{n}_{2 \mathrm{M}}$ is the total number of marker tests representing true null hypothesis (i.e., absence of linkage to QTL) among all marker tests (estimated as described in the next section); $\mathrm{P}_{\mathrm{C}}$ is the CWER significance threshold for declaring significance; and $\mathrm{R}_{\mathrm{C}}$ is the rank number of the marker test having $P$-value closest to $\mathrm{P}_{\mathrm{C}}$. However, in the present study involving 3 populations ( IsH, ItH, and combined) and 2 modes of analysis (SMM and MMM), this led to wide variation in threshold $P$-values among population-analysis combinations and to sets of significant results that were difficult to reconcile. For this reason, we chose a fixed CWER $P$-value $\left(\mathrm{P}_{\mathrm{C}}=\right.$ 0.02) that delivered PFP values generally close to the desired target $(\mathrm{PFP}=0.05)$ and used this to determine significance in all population-analysis combinations. For comparison purposes, PFP and FDR values at the fixed significance level were also calculated for all population-analysis combinations.

\section{Statistical Power and the Schweder-Spjøtvoll Plot}

The number of markers representing linkage to a QTL and statistical power of the experiment was estimated by the Mosig et al. (2001) iteration procedure and confirmed by Schweder-Spjøtvoll plot (Schweder and Spjøtvoll, 1982). In the Schweder-Spjøtvoll plot, marker tests are ranked by $\left(1-\mathrm{P}_{\mathrm{j}}\right)$, where $\mathrm{P}_{\mathrm{j}}$ is the $P$-value of the jth marker test and plotted against $\mathrm{R}_{\mathrm{i}} /$ $\mathrm{n}_{\mathrm{M}}$, where $\mathrm{R}_{\mathrm{i}}$ is the rank number of the jth marker test. Under the null hypothesis a regression coefficient of 1.0 is expected, yielding a $45^{\circ}$ regression line with intercept at 0.0 . If the tests originate from a mixture of true and falsified null hypotheses, the plot initially will be linear with regression coefficient less than 1.0, representing true null hypotheses almost exclusively. However, eventually the falsified null hypotheses will begin to affect the plot, causing it to curve upward sharply. Linearity of the initial portion of the plot confirms the validity of the standard error used to estimate the $P$-values. Extrapolation of the linear portion of the curve to intersect the $\mathrm{y}$-axis provides an estimate of the proportion of true null hypotheses among all $\mathrm{N}$ tests. The $\mathrm{n}_{2 \mathrm{M}}$ is obtained by multiplying the estimated proportion of null hypotheses by the total number of tests. The number of tests representing falsified null hypotheses is then estimated as $n_{1 M}=n_{M}-n_{2 M}$. Power of the test can now be calculated as $n_{\mathrm{OM}} / \mathrm{n}_{1 \mathrm{M}}$, where $\mathrm{n}_{\mathrm{OM}}$ is the observed number of marker tests declared significant according to the above criterion.

\section{Declaring a $Q T L$}

A QTL was declared based on 2 independent significant tests in one or more of the following combinations, namely whether it was signaled by significant markers in both the IsH and ItH populations, whether it was signaled by at least 2 neighboring markers significant by SMM in one of the individual populations or in the combined population, or whether it was signaled by at least 2 sires in the same or both populations. The requirement for 2 neighboring markers significant by SMM rather than by MMM was instituted because error variation is necessarily correlated across MMM $P$-values of neighboring markers but not across SMM $P$-values. Thus, 2 neighboring markers significant by SMM represent 2 truly independent evaluations of that chromosomal region for QTL content with respect to error variation, whereas they are mutually dependent in the case of neighboring markers significant by MMM. When several markers in a given region were significant, the marker with lowest $P$-value on MMM of the combined results was taken to represent the location of the QTL and the neighboring markers were considered as supporting markers. A QTL was declared only on the basis of a significant marker test. An intermarker interval that reached significance at some point between the 2 flanking markers on the basis of the MMM analysis but that was not supported by a significant marker was not considered to represent a QTL.

Two or more QTL on a single chromosome were declared when there were 2 peaks of marker significance more than $30 \mathrm{cM}$ apart across a chromosome on MMM analysis of the combined data sets, each peak meeting the criteria for declaring a QTL and separated by 1 or more markers of lower significance.

\section{Confidence Intervals for QTL Map Location}

Because our marker test statistic distributes as chisquared and following Manichaikul et al. (2006), confidence intervals for QTL map location were obtained using the chi-squared drop approximation equivalent to the logarithm of the odds (LOD) score drop approximation (Pérez-Enciso et al., 2000). The $95 \%$ confidence interval limits were obtained at chromosome locations where the test statistic decreased by chi-squared df (MMM), 0.95, where $\mathrm{df}(\mathrm{MMM})$ is obtained as described 
in Appendix II. This method performs reasonably well for QTL of large effect but is not as valid for QTL of small effect (Mangin et al., 1994).

\section{QTL Heterozygosity}

At the marker-trait level, a false null hypothesis represents a marker in linkage to a QTL. The proportion of false null hypotheses out of all $n_{M}$ marker-trait tests for a given trait $\left(\mathrm{n}_{1 \mathrm{M}} / \mathrm{n}_{\mathrm{M}}\right)$ thus represents the proportion of markers in linkage to QTL for the trait $\left(\mathbf{Q}_{\mathbf{M}}\right)$. At the sire-marker level, the proportion of false siremarker null hypotheses out of total sire-marker tests for a given trait $\left(\mathrm{n}_{1 \mathrm{SM}} / \mathrm{n}_{\mathrm{SM}} ; \mathbf{Q}_{\mathrm{SM}}\right)$ represents the product $\mathrm{Q}_{\mathrm{M}} \mathrm{H}$, where $\mathbf{H}$ is the proportion of QTL that are heterozygous in the sires. It follows that $\mathrm{Q}_{\mathrm{SM}}=\mathrm{Q}_{\mathrm{M}} \mathrm{H}$, and $\mathrm{H}$ can readily be estimated as $\mathrm{H}=\mathrm{Q}_{\mathrm{SM}} / \mathrm{Q}_{\mathrm{M}}$.

\section{QTL Allele Substitution Effects}

Allele substitution effects at the individual markers were calculated as described (Lipkin et al., 1998), based on Dtest $t_{i j}$ values for individual sire $\times$ marker combinations and mean EBV difference $\left(\mathrm{dEBV}_{\mathrm{i}}\right)$ of the high and low pools for the individual sires, taking into account the effect of selective genotyping (Darvasi and Soller, 1994). Because EBV for the Israel and Italian data were in terms of cEBV and rEBV, respectively, allele substitution effects were calculated separately for the IsH and ItH populations. Taking both values in $\mathrm{SD}$ units, IsH $/ \mathrm{SD}_{\text {IsH }}$ and $\mathrm{ItH} / \mathrm{SD}_{\mathrm{ItH}}$, brings them to a common basis. Hence, the effects calculated in ItH were converted to IsH basis by multiplying them by the SD ratio of the 2 populations:

$$
\mathrm{SD}\left(\mathrm{cEBV}_{\mathrm{IsH}}\right) / \mathrm{SD}\left(\mathrm{rEBV}_{\mathrm{ItH}}\right) \text {, }
$$

where, following Falconer and Mackay (1996), $\mathrm{SD}\left(\mathrm{cEBV}_{\mathrm{IsH}}\right)=\left(\mathrm{mdcEBV}_{\mathrm{IsH}}\right) / 2 \mathrm{i}_{\mathrm{P}, \mathrm{ISH}}$ and $\mathrm{SD}\left(\mathrm{rEBV}_{\mathrm{ItH}}\right)$ $=\left(\mathrm{mdrEBV}_{\mathrm{ItH}}\right) / 2 \mathrm{i}_{\mathrm{P}, \mathrm{ItH}}$, where mdcEBV $\mathrm{IsH}_{\mathrm{IsH}}$ is mean difference in cEBV across all IsH sires and $m \mathrm{mrEBV}_{\mathrm{ItH}}$ is mean difference in rEBV across all ItH sires. The variables $i_{P, I s H}$ and $i_{P, I t H}$ are the mean 1-tail selection intensities for $\mathrm{IsH}_{\mathrm{sH}}$ and $\mathrm{ItH}$, respectively, where $\mathrm{i}_{\mathrm{P}}$ is $\mathrm{z}_{\mathrm{P}} / \mathrm{P}, \mathrm{P}$ being the average proportion selected to each tail across all sires of IsH or ItH, respectively, and $\mathrm{z}_{\mathrm{P}}$ being the height of the ordinate of the standard normal distribution at the point of truncation beyond which the proportion $\mathrm{P}$ of the distribution falls (Falconer and Mackay, 1996). Values are divided by 2 because mdcE$\mathrm{BV}_{\text {IsH }}$ and mdrEBV $\mathrm{ItH}_{\text {It }}$ are the differences between the 2 tails, but selection intensity is measured from the mean to 1 tail.
Allele substitution effects within each population were obtained for each sire-marker combination significant at SMM $P \leq 0.10$ within markers that were significant at SMM $P \leq 0.02$. When several markers in a chromosomal region of 20 to $30 \mathrm{cM}$ in a given population were significant, all were considered to reflect linkage to the same QTL. In this case, the mean value of the estimated effects across all of the significant markers in the given region was taken as an estimate of the allele substitution effect at the presumed QTL. A QTL mapped to the same chromosomal region in both populations was considered to represent the same QTL, even if the chromosomal region was represented by different markers in the 2 populations. This is plausible because both populations are subpopulations of the Holstein breed. In this case we brought the ItH estimate to IsH basis as described above. Then, the allele substitution effect of the presumed QTL was calculated as the arithmetic mean of the IsH and transformed ItH estimates.

\section{Total Proportion of Variation in EBV SCS Explained by the Mapped QTL}

A unique aspect of the present study was our ability to estimate the allele substitution effects of the mapped QTL $\left(\alpha_{j}\right)$ and $H$. With this information, the variance in EBV SCS contributed by each QTL can be estimated as

$$
\operatorname{Var}\left(\mathrm{QTL}_{\mathrm{k}}\right)=\mathrm{H}_{\mathrm{k}} \mathrm{\alpha}_{\mathrm{j}}^{2}
$$

For the present analysis we used the global heterozygosity estimate $\mathrm{H}=0.442$ obtained from our data. This will not be far from the actual value over a wide range of allele frequencies. The proportion of total EBV variance explained by the kth QTL will then be $\operatorname{Var}\left(\mathrm{QTL}_{\mathrm{k}}\right) /$ $\mathrm{SD}^{2}\left(\mathrm{cEBV}_{\text {IsH }}\right) ; \mathrm{SD}^{2}\left(\mathrm{cEBV}_{\text {IsH }}\right)$ is used because the ItH effects were brought to IsH basis.

\section{Effect on EBV SCC of a QTL with Given Effect on EBV SCS}

Transforming the Ali and Shook (1980) expression appropriately, SCC can be estimated from reported SCS values for milliliters as

$$
\mathrm{SCC}_{\mathrm{mL}}=(100,000) 2^{(\mathrm{SCS}-3)} .
$$

Because Israel base value is SCS $=2.94$ and Italy base value is $\mathrm{SCS}=2.9$, it is convenient to take base value as 3.0 (equivalent to $\mathrm{SCC}=100,000$ cells $/ \mathrm{mL}$ ). The effect on EBV SCS of animals carrying the positive versus the negative sire QTL allele at marker $\mathrm{j}$ can then 
Table 1. Characteristics of the Israeli and Italian Holstein samples ${ }^{1}$

\begin{tabular}{|c|c|c|c|c|c|c|c|c|}
\hline Sire & $\mathrm{No}^{2}$ & Proportion $^{3}$ & Intensity $^{4}$ & \multicolumn{2}{|c|}{ Sampled $^{5}$} & \multicolumn{3}{|c|}{ Mean EBV SCS ${ }^{6}$} \\
\hline \multicolumn{9}{|l|}{ Israel Holstein } \\
\hline 2 & 5,193 & 0.050 & 2.007 & 211 & 193 & 3.02 & 2.67 & 0.34 \\
\hline 3 & 1,644 & 0.158 & 1.486 & 196 & 193 & 2.95 & 2.69 & 0.26 \\
\hline 4 & 6,408 & 0.041 & 2.092 & 196 & 197 & 3.13 & 2.56 & 0.57 \\
\hline \multicolumn{9}{|l|}{ Italian Holstein } \\
\hline 1 & 6,911 & 0.038 & 2.129 & 199 & 186 & 3.58 & 2.73 & 0.85 \\
\hline 2 & 3,311 & 0.079 & 1.810 & 180 & 164 & 3.00 & 2.31 & 0.69 \\
\hline 3 & 3,846 & 0.068 & 1.876 & 163 & 138 & 3.22 & 2.50 & 0.72 \\
\hline 4 & 3,603 & 0.072 & 1.847 & 154 & 155 & 3.21 & 2.51 & 0.70 \\
\hline 5 & 3,189 & 0.082 & 1.793 & 180 & 170 & 3.05 & 2.39 & 0.66 \\
\hline
\end{tabular}

${ }^{1}$ High = high SCS group (i.e., more susceptible); Low = low SCS group (i.e., more resistant); Diff = high minus low.

${ }^{2}$ Total number of listed milking daughters of the sire.

${ }^{3}$ Proportion of the 260 targeted daughters per tail out of all listed daughters.

${ }^{4}$ Selection intensity (260 daughters per tail).

${ }^{5}$ Number of target daughters actually sampled to each tail.

${ }^{6}$ See text for details on bringing Israel and Italy reported EBV SCS scores to the same basis.

be calculated from the above expressions by taking the difference as the allele substitution effect in SCC units, giving

$$
\alpha_{\mathrm{j}} \text { in units of } \mathrm{SCC}_{\mathrm{mL}}=100,000\left[2^{\left(\alpha_{\mathrm{j}} / 2\right)}-2^{\left(-\alpha_{\mathrm{j}} / 2\right)}\right] .
$$

For small allele substitution effects as in our case, the above expression for cells per milliliter equals $100,000\left(2^{\alpha_{\mathrm{j}}}-1\right)$. Effects obtained in this way should be evaluated relative to the total range of EBV SCC, which can be estimated using the above expressions for allele substitution effect as

$$
\begin{aligned}
& \text { total range of } \mathrm{EBV} \mathrm{SCC} / \mathrm{mL}= \\
& 100,000\left[2^{2 \mathrm{SD}\left(\mathrm{cEBV}_{\mathrm{IsH}}\right)}-2^{-2 \mathrm{SD}\left(\mathrm{cEVB}_{\mathrm{IsH}}\right)}\right],
\end{aligned}
$$

where $\mathrm{SD}\left(\mathrm{cEBV}_{\mathrm{IsH}}\right)$ is defined and calculated as above.

\section{RESULTS}

\section{Characteristics of the Israeli and Italian Samples}

Table 1 shows the total number of daughters of each sire, the proportion of the total targeted for sampling for each tail, the mean cEBV SCC (IsH) or rEBV SCC (ItH) of the daughters actually sampled to the high and low tails, and the difference between the 2 tails. Total numbers of daughters of the sampled sires were 20,451 and 30,402 and average proportions targeted for each tail were 0.099 and 0.066 for IsH and ItH, respectively. The proportion of targeted daughters actually collected was virtually identical for the high and low tails (78 and $77 \%$, respectively, for IsH and 65 and $66 \%$, respectively, for ItH), indicating that selection was not being applied in the herds with respect to SCS. The lower proportion of targeted individual sampled in ItH is attributed to a delay of about 6 mo between selection of the target daughters at the central database and actual sampling of the daughters by the local breeder associations. In the interval, many daughters were culled. Mean EBV SCS of the 2 subpools in each tail were very similar so that only the mean values across the 2 subpools of each tail are shown.

The high-low difference in rEBV (0.336) of daughters selected on cEBV was $73 \%$ of that for daughters selected on rEBV (0.462). Similarly, the high-low difference in cEBV of daughters selected on rEBV (0.223) was also $73 \%$ of that for daughters selected on cEBV (0.304). Thus, the daughters that were selected by one criterion were still quite strongly selected with respect to the alternative criterion. Consequently, the high-low pools can be assumed to differ with respect to EBV for MSCC, whether measured as rEBV or cEBV.

Mean cEBV SCS and rEBV SCS for the high tails were almost the same for IsH and ItH (3.03 and 3.14 SCS units, corresponding to SCC of 102,000 and 
a) Israel

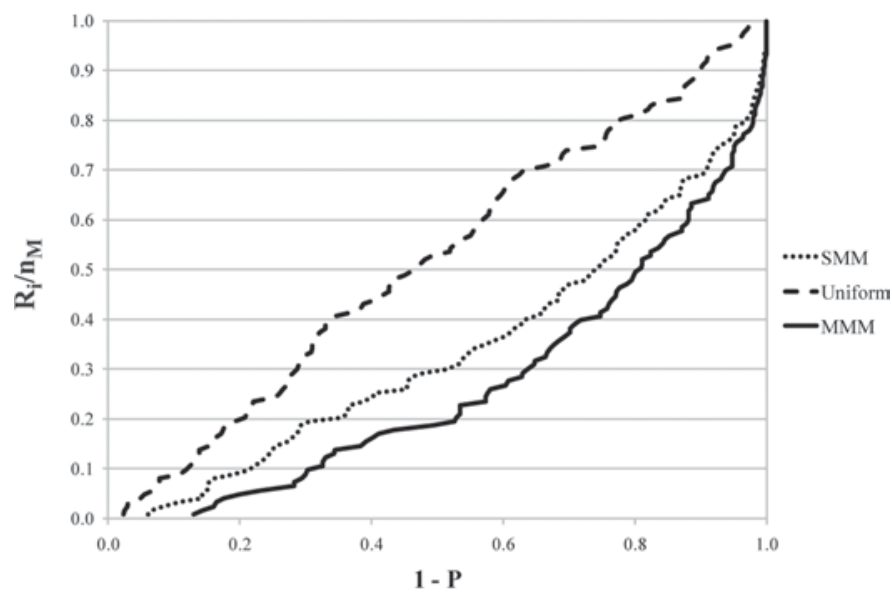

b) Italy

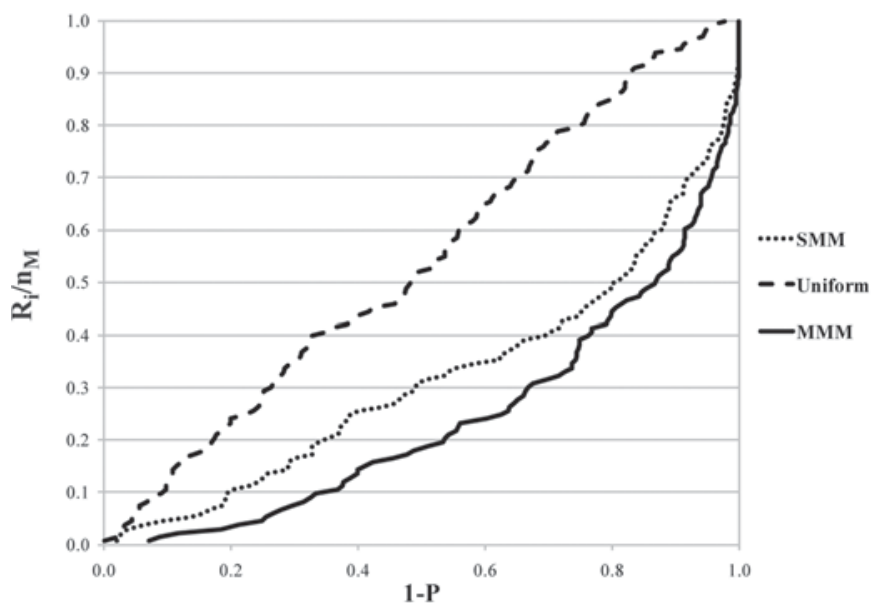

c) Combined

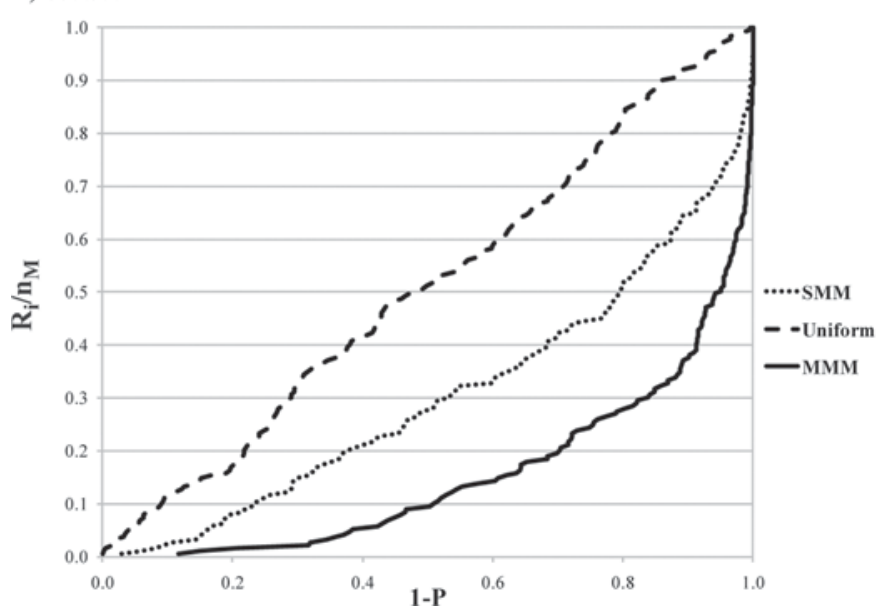

Figure 1. Schweder-Spjøtvoll (Schweder and Spjøtvoll, 1982) plots for single-marker mapping (SMM), multiple-marker mapping (MMM), and a uniform distribution. a) Israel; b) Italy; c) combined. $\mathrm{R}_{\mathrm{i}}=$ rank number; $\mathrm{n}_{\mathrm{M}}=$ total number of marker tests performed.
$114,000 / \mathrm{mL}$, respectively) but differed more for the low tails (2.70 and 2.41 SCS units, corresponding to SCC of 81,000 and $66,000 / \mathrm{mL}$, respectively).

The SD of EBV SCS for SCS can be estimated from the proportion selected and the observed difference between the tails as follows:

$$
\begin{gathered}
\mathrm{SD}\left(\mathrm{cEBV}_{\mathrm{IsH}}\right)=0.33 /(2 \times 1.756)=0.094, \text { and } \\
\mathrm{SD}\left(\mathrm{rEBV}_{\mathrm{ItH}}\right)=0.73 /(2 \times 1.906)=0.191
\end{gathered}
$$

\section{Empirical $S D(D n u l l)_{i j}$}

Empirical SD(Dnull $)_{\mathrm{ij}}$ for the IsH and ItH data sets was estimated as 0.045 and 0.040 , respectively. Using $\mathrm{SD}(\text { Dnull })_{\mathrm{ij}}$, the $P$-values for the Dnull ${ }_{\mathrm{ij}}$ values should present a uniform distribution. In particular, we expect 0.50 of all $P$-values to fall in the 1.00 to $0.50 P$-value bin. Indeed, for IsH, ItH, and combined data, 0.557, 0.579, and 0.575 of all Dnull $\mathrm{ij}_{\mathrm{ij}} P$-values, respectively, were in this bin. In all cases, the deviation from 0.50 was far from significant by chi-squared test. In contrast, for the MMM tests, the Dnull ${ }_{\mathrm{ij}} P$-values presented 0.578, 0.613, and 0.676 in the 1.00 to 0.50 bins for IsH, ItH, and combined data, respectively. The deviations from expected were not significant for IsH but approached 0.05 significance level for ItH and were highly significant for the combined data, even after Bonferroni correction. Thus, the MMM test in practice may have been less stringent than the nominal $P$-values obtained by this method indicate.

\section{Schweder-Spjøtvoll Plots}

Figure 1 shows Schweder-Spjøtvoll plots for SMM and MMM marker tests based on Dtest $(1-\mathrm{P})$ values separately for the IsH (Figure 1a), ItH (Figure 1b), and combined data (Figure 1c) sets. For comparison, each figure also shows a plot of $(1-\mathrm{P})$ values sampled from a uniform distribution (Pnull).

In all cases, the $P$-values for the Dtest plots (SMM and MMM) were well below a uniform distribution (Pnull plot) across the range $(1-\mathrm{P}) 0.00$ to 0.50 , indicating that a major portion of the Dtests represent falsified null hypothesis. In this range, the Dtest $(1-\mathrm{P})$ values show a clear linear trend, and the linear regression fitted to the data points from $(1-\mathrm{P})=0.00$ to $(1-\mathrm{P})$ $=0.50$ shows a close fit to the observed data points, testifying to the validity of the $\mathrm{SD}$ (Dnull) values used to calculate the $P$-values of the Dtest values. This also indicates that falsified null hypotheses rarely generate $P$-values in the range 1.00 to 0.50 . The number of true 
Table 2. Summary statistics of marker tests ${ }^{1}$

\begin{tabular}{|c|c|c|c|c|c|c|}
\hline Item $^{2}$ & \multicolumn{2}{|c|}{ Israel $(\mathrm{n}=123)$} & \multicolumn{2}{|c|}{ Italy $(\mathrm{n}=133)$} & \multicolumn{2}{|c|}{ Combined $(\mathrm{n}=189)$} \\
\hline $\mathrm{n}_{1}\left(\mathrm{Pn}_{1}\right)$ & $51(0.42)$ & $77(0.63)$ & $57(0.43)$ & $85(0.64)$ & $86(0.46)$ & $155(0.82)$ \\
\hline $\mathrm{PFP}$ & 0.071 & 0.037 & 0.067 & 0.032 & 0.051 & 0.009 \\
\hline FDR & 0.121 & 0.099 & 0.118 & 0.090 & 0.093 & 0.050 \\
\hline $\mathrm{n}_{\mathrm{O}}$ & 20 & 25 & 23 & 31 & 40 & 72 \\
\hline
\end{tabular}

${ }^{1} \mathrm{n}=$ total number of marker tests. SMM = single-marker mapping; MMM = multiple-marker mapping.

${ }^{2} \mathrm{n}_{1}=$ estimated number of true null hypotheses; $\mathrm{Pn}_{1}=$ proportion of true null hypotheses; $\mathrm{n}_{2}=$ estimated number of falsified null hypotheses; $\mathrm{Pn}_{2}=$ proportion of falsified null hypotheses; PFP $=$ proportion of false positive critical values corresponding to $P=0.02$ threshold; FDR $=$ false discovery rate critical values corresponding to $P=0.02$ threshold; $\mathrm{n}_{\mathrm{O}}=$ number of significant tests; power $=$ estimated power of the experiment.

null hypotheses inferred by extrapolation of the linear regression were $73.2,83.0$, and 105.2 for SMM tests of IsH, ItH, and combined data, respectively, and 46.4, 49.0, and 36.0 for the MMM tests of IsH, ItH, and combined data, respectively. These are very close to the estimates of the number of true null hypotheses obtained by the Mosig et al. (2001) iteration procedure (Table 2).

Beyond this, in the region $(1-\mathrm{P})=0.50$ to 1.00 , the Dtest $(1-\mathrm{P})$ values deviate more and more in an upward direction from the extrapolation of the linear trend. The increasing difference between the observed $\mathrm{P}$-plot in this region and the linear extrapolation of the 0.00 to 0.50 plot can be attributed to the increasing proportion of marker tests that represent falsified null hypotheses among all marker tests that present $(1-\mathrm{P})$ values in this region.

\section{Significance, PFP, FDR, and Statistical Power}

The number and proportions of true and of falsified null hypotheses, PFP and FDR values, and statistical power were very similar between IsH and ItH (Table 2) when taking into account the larger number of markers analyzed in ItH. As expected, FDR values at the fixed $P=0.02$ significance level were higher than the corresponding PFP values, but both PFP and FDR were well within acceptable bounds. In both populations the estimated number of falsified null hypotheses $\left(\mathbf{n}_{1}\right)$ and proportion of falsified null hypotheses were about $50 \%$ higher under MMM compared with SMM. Thus, for the present data set, the increase in MMM test statistics more than balanced the increase in MMM df. For the same reason, the number of markers reaching the $P \leq$ 0.02 significance level $\left(\mathbf{n}_{\mathbf{O}}\right)$ was greater under MMM than under SMM. Because both $\mathrm{n}_{\mathrm{O}}$ and $\mathrm{n}_{1}$ are greater under MMM than SMM, statistical power calculated as the ratio of the $2\left(n_{0} / n_{1}\right)$ was about the same for the
2 methods $(0.33$ and 0.37 averaged across IsH and ItH, respectively).

For the combined data sets, the markers reaching significance under SMM were the same as those that were significant in the individual IsH or ItH analyses, either in one population alone or in both. Additional significant markers were not found. For MMM, however, many additional markers along the chromosome generated significant $P$-values for the combined data set. For the most part, however, the additional significant markers simply extended the region of significance on a chromosome carrying a QTL but did not uncover additional QTL. This is reasonable because in principle all markers on a chromosome are to some extent in linkage with a QTL at any location on that chromosome, and this would be uncovered by a sufficiently powerful test. More detailed comparison of SMM and MMM is deferred to the Discussion section.

\section{QTL Heterozygosity}

Based on the combined data of the 2 populations, a total of 189 marker tests and 1,149 sire-marker tests were performed. Of these, 86 marker tests (Table 2) and 231 sire marker tests (data not shown) were found to represent falsified null hypotheses by application of the Mosig et al. (2001) iteration procedure. Thus, the proportion of falsified null hypothesis was $\mathrm{Q}_{\mathrm{M}}=0.455$ at the marker level and $\mathrm{Q}_{\mathrm{SM}}=0.201$ at the sire-marker level, giving $\mathrm{H}=0.442$.

\section{Marker Tests}

Table 3 shows the distribution of significant marker tests (at CWER $P \leq 0.02$ ) by chromosome and population (IsH, ItH, and combined data). Without exception, all markers significant by SMM were also significant by MMM, but the converse was not true; a small propor- 
tion of markers were significant by MMM alone. Also, in about $70 \%$ of cases, for markers that were significant both for SMM and MMM, the level of significance was higher (i.e., $P$-values were lower) for MMM than for SMM. This is to be expected because MMM is based on more information than SMM.

Twenty-one markers were significant in IsH only, 26 in ItH only, and 4 in both populations, for a total of 51 significant markers across both populations (note that some of the markers were tested in 1 population only). Of these, 40 were significant for the combined data by both SMM and MMM, whereas 8 were significant for MMM alone. These were distributed across 24 chromosomes (all autosomes except for BTA 5, 15, 18, 21, and 23).

At the chromosome level, 9 chromosomes (BTA 1, 3, $4,9,14,20,27,28$, and 29) carried significant markers in both populations (not necessarily the same chromosomal region); 7 chromosomes (BTA 6, 8, 12, 13, 22, 24, and 25) carried significant markers in IsH only; and 8 chromosomes (BTA 2, 7, 10, 11, 16, 17, 19, and 26) carried significant markers in ItH only. The added markers significant for MMM alone extended the regions of significance on the chromosomes implicated by markers significant for both SMM and MMM but did not add any new chromosomes to the list.

\section{Declaration of QTL}

A total of 22 QTL were identified (Table 4) on BTA 1, 2, 3, 4, 6 (proximal), 6 (distal) $7,8,9,10,11,12$, $13,14,17,19,20,24,26,27,28$ and 29. Of these, 10 were identified by significant markers in both IsH and ItH (BTA 1, 3, 4, 13, 14, 17, 20, 27, 28, and 29). Both BTA13 and BTA17 were included in this group, although significant for only a single marker in a single chromosome because each had a single significant sire in each population. Of the remaining chromosomes, 5 were significant in IsH alone [BTA 6 (proximal), 6 (distal), 8, 12, and 24] and 7 were significant in ItH alone (BTA 2, 7, 9, 10, 11, 19, and 26). The high proportion of QTL appearing in both populations under these criteria $(45 \%)$ is unexceptional because this was one of the criteria for declaring a QTL. Figure 2a shows MMM plot for BTA6, which we interpret as presenting 2 QTL. Figure 2b shows MMM plot for BTA2, which is typical of chromosomes presenting only a single QTL. A whole genome synoptic view of the SMM for the combined analysis showing location and confidence interval of the declared QTL is presented in Figure 3.

All chromosomes carrying QTL in the present study were also identified as carrying QTL affecting SCS or clinical mastitis by studies summarized in the QTL databases. In most cases, a reported QTL was not far from the QTL locations presented here (Table 4).

Allele substitution effects (Table 4) ranged from 0.0171 to 0.0376 in EBV SCS units (mean $=0.0251$ ) and from 1,192 to 2,653 cells/mL in EBV SCC units (mean $=1,757$ cells $/ \mathrm{mL})$. The distribution of effects was basically uniform. Standardized allele substitution effects, as a proportion of the SD of EBV SCS, ranged from 0.18 to 0.40 (mean $=0.27$ ). This is comfortably within the range of QTL effects found over a wide range of studies. On the assumptions listed in the Materials and Methods section, the proportion of variance in EBV SCS explained by individual QTL ranged from 0.0153 to 0.0939 and averaged 0.0369 (Table 4).

\section{DISCUSSION}

\section{Selection Differential Between High and Low Tails for the Israeli and Italian Samples}

Overall selection differential between high and low tails for IsH (0.33 SCS units) was only $45 \%$ of that for ItH (0.73 SCS units). Two technical factors contribute to this: 1) as stated above, the difference between high and low tails for cEBV of daughters selected by cEBV was $65.8 \%$ of the difference in rEBV of daughters selected by rEBV, and 2) the proportion selected to each tail in ItH (0.066) was more intense than in IsH (0.099), giving selection intensities equal to 1.906 and 1.756 , respectively. Consequently, the selection differential for IsH was only 0.921 of that for ItH. Correcting for both factors, we obtain Israel equivalent selection differential between high and low tails of ItH $=0.73 \times 0.658 \times$ $0.921=0.442$ SCS units. Thus, even after these corrections, SCS difference for the Israeli data (0.33) remains only two-thirds that for the Italian data. The actual distribution of IsH SCS values deviates from the standard normal distribution on which the calculation of selection intensities is based, in having a minor mode in the left hand tail (J. Weller, Agricultural Research Organization, Bet Dagan, Israel; personal communication). This may be responsible at least in part for the remaining difference.

\section{Comparison of SMM and MMM}

Under SMM, marker test statistics depend in large part on the number of sires that were heterozygous at the marker and QTL state (homozygous or heterozygous) at these sires. Consequently, SMM marker test statistics can fluctuate strongly across a chromosome, making it difficult to distinguish random fluctuations from multiple QTL. In contrast, under MMM a marker 
Table 3. Significant markers tests ${ }^{1,2,3}$

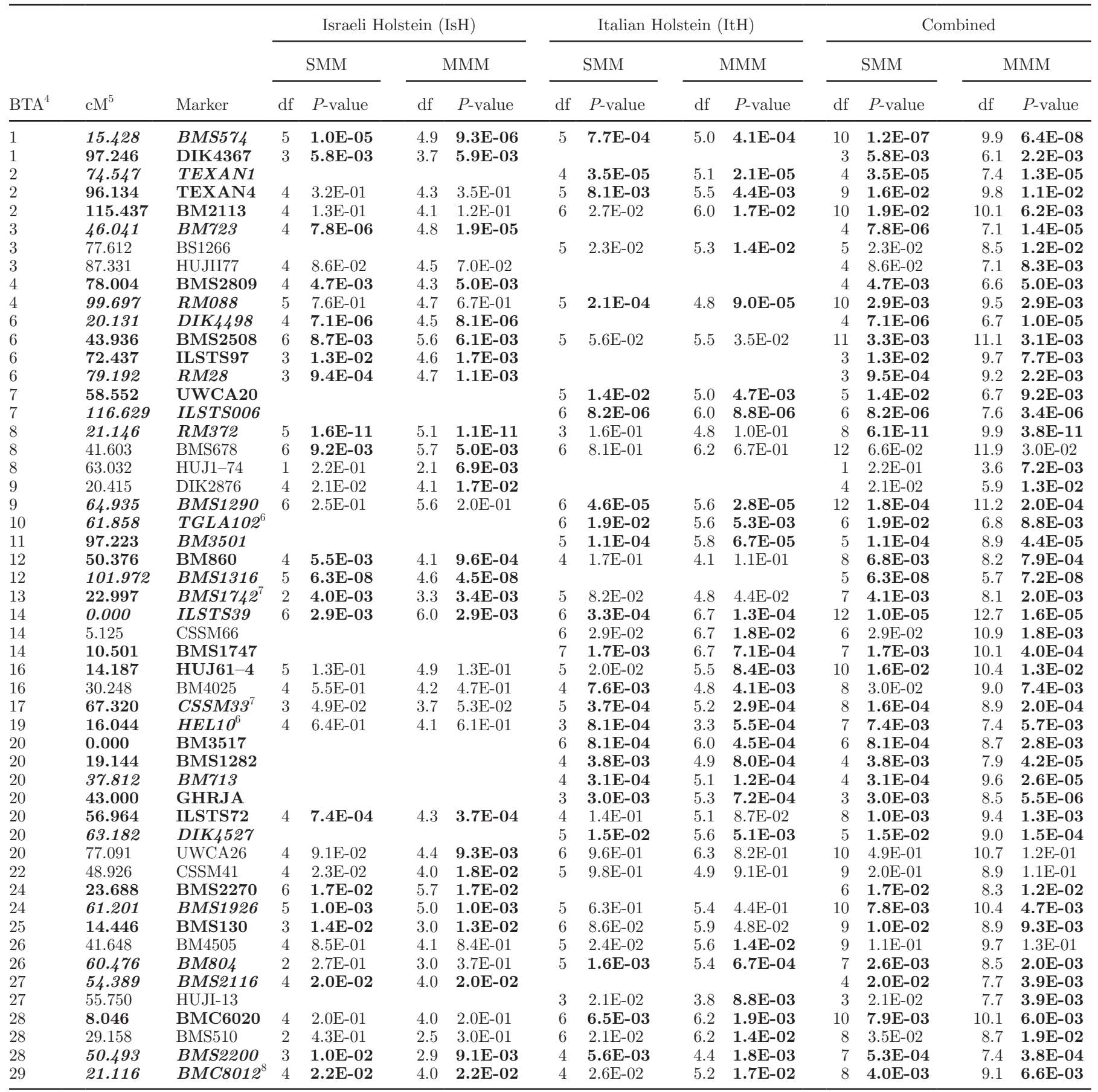

${ }^{1}$ For IsH and ItH populations, all significant markers are included, whether by SMM or MMM. For combined population, only markers significant by both SMM and MMM are included. Marker $P$-values are shown for all populations even if significant only for a single population and a single analysis. In a few cases, almost significant markers are shown when they support an adjacent significant marker.

${ }^{2} \mathrm{SMM}=$ single-marker mapping; $\mathrm{MMM}=$ multiple-marker mapping; $P$-value $=$ comparison-wise error rate $P$-values.

${ }^{3} \mathrm{~A}$ bold $P$-value indicates that the marker is significant at $P \leq 0.02$. Marker name and location in bold text indicates that the marker was significant by MMM but was not used for declaring a QTL. Marker name and location in bold italic text indicates a marker used for declaring a QTL. Marker name and location in plain text indicates a marker supporting a QTL.

${ }^{4}$ Chromosome.

${ }^{5}$ Location (centimorgans on USDA Meat Animal Research Center map; http://www.marc.usda.gov/genome/cattle/cattle.html).

${ }^{6}$ Two ItH sires significant.

${ }^{7}$ One sire significant in each population.

${ }^{8}$ Borderline significance in IsH. 
Table 4. Identified QTL

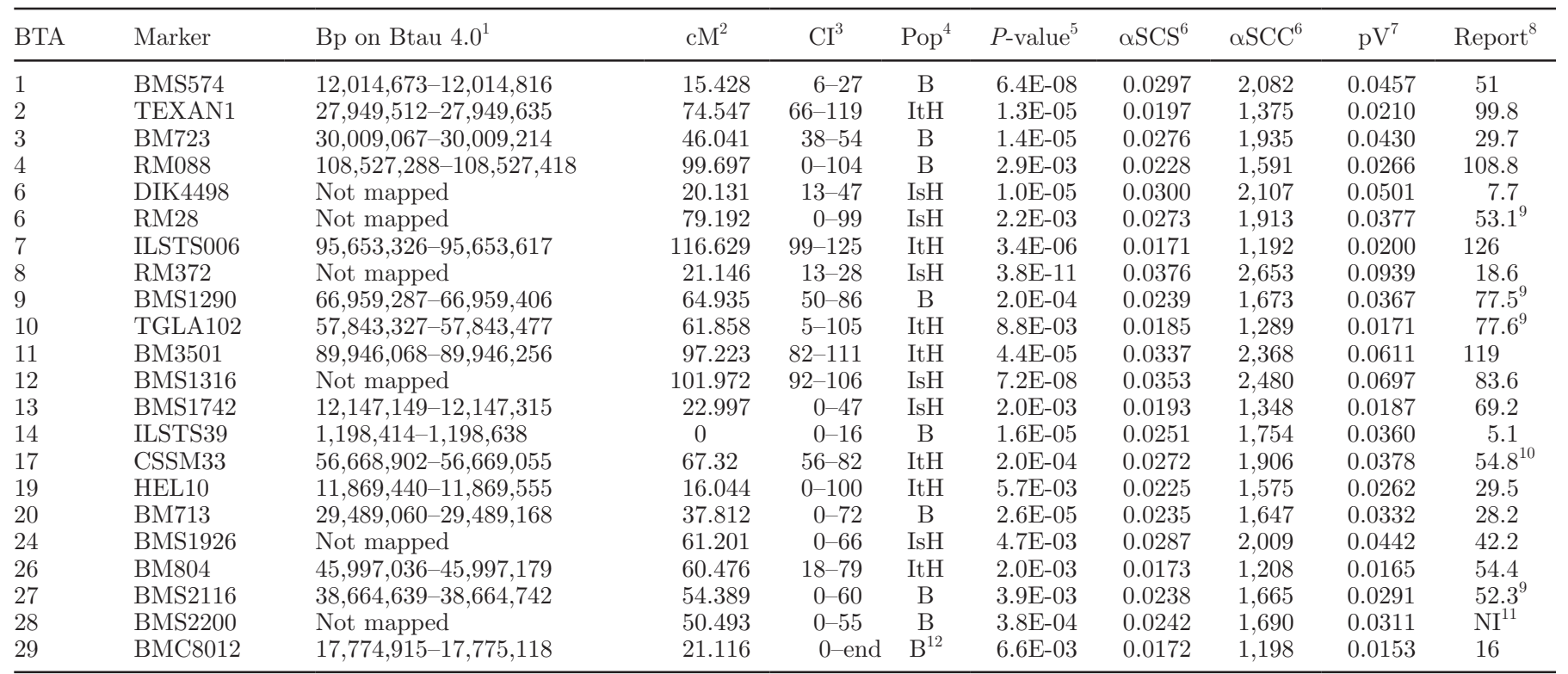

${ }^{1}$ Btau 4.0, the most recent assembly of the bovine genome; http://www.ensemble.org/Bos_taurus/Info/Index.

${ }^{2}$ Location (centimorgans on USDA Meat Animal Research Center map; http://www.marc.usda.gov/genome/cattle/cattle.html).

${ }^{3} 1.0$ chi-squared drop confidence interval (centimorgans) of QTL map location.

${ }^{4} \mathrm{Pop}=$ populations in which QTL found. IsH = Israel Holstein; ItH = Italy Holstein; B = both.

${ }^{5} P$-value according to multiple-marker mapping analysis of combined data.

${ }^{6}$ Estimated allele substitution effect.

${ }^{7}$ Estimated proportion of explained EBV variance.

${ }^{8}$ Map location (centimorgans) of closest reported QTL affecting SCS or clinical mastitis in the Web databases (Khatkar et al., 2004; Polineni, 2004; Hu and Reecy, 2007).

${ }^{9}$ Report for clinical mastitis.

${ }^{10}$ Alessandro Bagnato, University of Milan, Milan, Italy; unpublished data.

${ }^{11} \mathrm{QTL}$ reported for the chromosome but no information on the QTL location.

${ }^{12}$ Borderline significance in IsH.

that is homozygous in a sire still makes a contribution to the overall marker test statistic derived from those markers that are heterozygous in that sire. Consequently, MMM generates a smooth plot that appears to provide a more realistic picture of distribution of QTL effects along the chromosome. Furthermore, the MMM analysis allows use of the chi-squared drop method to set confidence intervals for QTL location. This is not possible with SMM.

For the same reasons, MMM can generate significance at markers that did not reach significance under SMM. As noted in the Results section, however, the additional significant markers under MMM did not uncover additional QTL compared with SMM, but only extended the region of marker significance on chromosomes that were significant by SMM. Thus, our recommendation would be to use SMM for first stage QTL mapping and MMM to obtain confidence interval of QTL location and more accurate assessment of the number of QTL on a chromosome.

\section{QTL Affecting SCS and Milk Production Traits}

A total of 15 QTL affecting EBV SCS were identified in the IsH population. Of these, $9(60 \%)$ were located in chromosomal regions that affected milk production traits (i.e., milk yield, milk protein percentage, protein yield) previously mapped in the same population (Lipkin et al., 2008). Comparable data were not available for the ItH population. Considering that power of the experiment was only moderate, this suggests that a high proportion of loci affecting SCS also affect milk production traits and vice versa. Examination of the comprehensive QTL database for milk traits, SCS, and CM presented in a recent review (Ogorevc et al., 2009) also shows $80 \%$ overlap of chromosomal regions affecting the milk production traits and those affecting SCS or CM (calculations not shown). Because confidence intervals of QTL map location were very wide, part of the overlap may be attributed to different loci mapped to the same general region. Yet another part of may be 
attributed to direct effects of the stress associated with high milk production on susceptibility to mastitis infection and of the reverse direct effect of mastitis infection on milk production. Still, we would have expected the bulk of QTL affecting SCS to act by way of the immune defense system and not to be so closely associated with milk production traits.

Of the 22 QTL declared, 10 were identified in both populations whereas the remainders were identified in one population only. A recent study of the Australian Holstein population (Zenger et al., 2007), however, showed that it could be considered a part of the global Holstein population and was not differentiated from it. The same should apply to the IsH and ItH populations. Summing the values given in Table 4 across QTL identified in one or both of the populations, the total proportion of variation in EBV SCS explained by the identified QTL was 0.81. This estimate is subject to 2 balancing caveats. On the one hand, when power is incomplete, estimated allele substitution effects are biased upward. Thus, the proportion of total variance in EBV values explained by the QTL actually mapped in the present study is overestimated. On the other hand, because power was not complete, this means that additional QTL that were not captured in the present study are affecting SCS. Indeed, the QTL databases report QTL affecting SCS or CM on several chromosomes (e.g., BTA 5, 18, 21, 22, 23, and 25), whereas we did not locate such QTL. Thus, it is possible that virtually all genetic variation in SCS can be anchored at individual QTL with effects strong enough to map to high resolution using whole genome association methods. The results presented here provide a basis for such studies. Potentially, all genetic variation in SCS may be accessible to marker-assisted selection or gene-assisted selection.

\section{Current and Potential Range of EBV SCC Values}

It is of interest to compare the current lower limit of EBV SCS values in the population with the potential mean that could be obtained by fixation of all alleles reducing EBV SCS that were identified in the present study. Taking the $95 \%$ lower limit of values in a population as the mean $-2 \mathrm{SD}$, we have mean $\mathrm{SCS}=3.0$ and $\mathrm{SD}$ of cEBV SCS for IsH $=0.091$, giving a $95 \%$ lower limit in cEBV SCS for Israel of 2.81. Translating this into SCC units gives lower limit of $\mathrm{cEBV} \mathrm{SCC} / \mathrm{mL}=$ 87,800 cells $/ \mathrm{mL}$. Note that milk from uninfected udders presents about 50,000 cells/mL (Laevens et al., 1997; Schepers et al., 1997). Thus, under the present genetic architecture, even cows at the lower end of the range are likely to undergo at least 1 infection that results in high recorded SCC. a)

BTA6



b)

\section{BTA2}

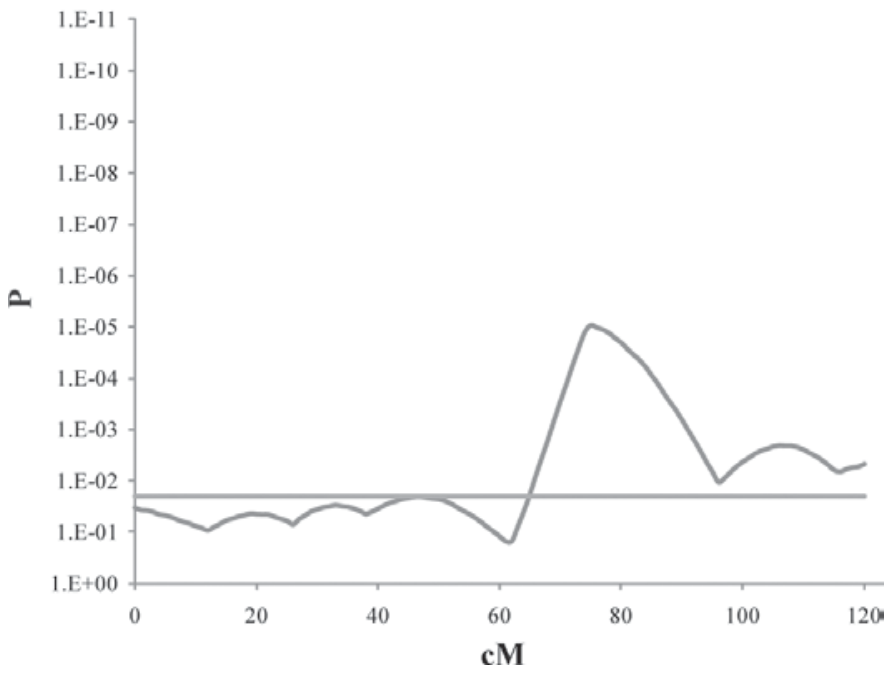

Figure 2. Multiple-marker mapping $P$-value plots for the combined analyses. a) Plot for BTA6, which was interpreted as presenting 2 QTL. b) Plot for BTA2 illustrating a chromosome presenting a single QTL. The threshold lines show $P=0.02$.

In a more speculative mode, we now calculate the expected population mean at the selection limit for low SCS. Twenty-two QTL had mean allele substitution effect 0.0251. Assuming current allele frequencies at these QTL averaging 0.5, on fixation of all alleles having a reducing effect on EBV SCS, mean EBV SCS in the selection line would be $3.0-22 \times 0.0251=2.45$. Translated to SCC units, this would be 68,000 cells/ $\mathrm{mL}$. Thus, mean population EBV of the low SCS selection line would transcend the current extreme low EBV values and closely approach the 50,000 cells/mL typical of uninfected udders. At this mean EBV level, an ap- 




Figure 3. A whole genome view of the single-marker mapping for the combined analysis. SMMm $=$ marker SMM $P$-value.

preciable proportion of cows may never undergo even a single infection that results in high recorded SCC. Furthermore, at a lower selection limit of 50,000 cells/ $\mathrm{mL}$, the cell count at the end of the process would be typical of that of an uninfected udder and little genetic variation would remain. This implies that even at the limit the reduction in EBV SCS achieved by selection would be primarily at the level of number and severity of mastitis infections rather than at the level of cell number in the uninfected udder. This is reassuring in view of expressed concerns that selection for low SCC may reduce immune cells in the uninfected udder below the level needed to mount an effective fight against pathogen invasion.

\section{ACKNOWLEDGMENTS}

This research was supported by the Regione Lombardia (Milan, Italy), Programma Regionale di Ricerca 2004-2006, Project n. 837, PRIN2007 MIUR funds; the United States-Israel Binational Agricultural Research and Development Fund (BARD, Bet Dagan, Israel) Project No. US-3406-03 R; Israel Cattle Breeders As- sociation (Caesaria Industrial Park); and Tnuva marketing cooperative. Support was also provided by the European Commission (Brussels, Belgium) within the 5th Framework Program, Grant Agreement QLK5CT-2001-02379 ("BovMAS") and within the 7th Framework Program, Grant Agreement KBBE-2A-222664 ("Quantomics"). The text represents the authors' views and does not necessarily represent a position of the Commission, who will not be liable for the use made of such information. M. Dolezal was supported by FWFgrant L403-B11 to Christian Schlötterer (Veterinary Institute, Vienna, Austria). We thank A. B. Samorè (Veterinary Faculty, University of Milan, Italy) for important suggestions.

\section{REFERENCES}

Ali, A. K. A., and G. E. Shook. 1980. An optimum transformation for somatic cell concentration in milk. J. Dairy Sci. 63:487-490.

Bagnato, A., F. Schiavini, A. Rossoni, C. Maltecca, M. Dolezal, I. Medugorac, J. Sölkner, V. Russo, L. Fontanesi, A. Friedmann, M. Soller, and E. Lipkin. 2008. Quantitative trait loci affecting milk yield and protein percent in a three-country Brown Swiss population. J. Dairy Sci. 91:767-783. 
Benjamini, Y., and Y. Hochberg. 1995. Controlling the false discovery rate: A practical and powerful approach to multiple testing. J.R. Stat. Soc. 57:289-300.

Darvasi, A., and M. Soller. 1994. Selective DNA pooling for determination of linkage between a molecular marker and a quantitative trait locus. Genetics 138:1365-1373.

Dolezal, M. 2007. Improvements in selective DNA pooling for quantitative trait locus mapping in dairy and dual purpose cattle. $\mathrm{PhD}$ Thesis. Univ. of Natural Resources and Applied Life Sci., Vienna, Austria.

Dolezal, M., H. Schwarzenbacher, M. Soller, J. Sölkner, and P. M. Visscher. 2008. Multiple-marker mapping for selective DNA pooling within large families. J. Dairy Sci. 91:2864-2873.

Dunklee, J. S., A. E. Freeman, and D. H. Kelley. 1994. Comparison of Holsteins selected for high and average milk production. 2. Health and reproductive response to selection for milk. J. Dairy Sci. $77: 3683-3690$

Falconer, D. S., and T. F. C. Mackay. 1996. Introduction to Quantitative Genetics. 4th ed. Longmans Green, Harlow, UK.

Fernando, R. L., D. Nettleton, B. R. Southey, J. C. M. Dekkers, M. Rothschild, and M. Soller. 2004. Controlling the proportion of false positives (PFP) in a multiple test situation. Genetics 166:611619

Hansen, L. B., C. W. Young, K. P. Miller, and R. W. Touchberry. 1979. Health care requirements of dairy cattle. I. Response to milk yield selection. J. Dairy Sci. 62:1922-1931.

Heringstad, B., G. Klemetsdal, and J. Ruane. 2000. Selection for mastitis resistance in dairy cattle- $\mathrm{A}$ review with focus on the situation in the Nordic countries. Livest. Prod. Sci. 64:95-106.

Hu, Z. L., and J. M. Reecy. 2007. Animal QTLdb: Beyond a repository. A public platform for QTL comparisons and integration with diverse types of structural genomic information. Mamm. Genome $18: 1-4$.

Kemp, M. H., A. M. Nolan, P. J. Cripps, and J. L. Fitzpatrick. 2008. Animal-based measurements of the severity of mastitis in dairy cows. Vet. Rec. 163:175-179.

Khatkar, M. S., P. C. Thomson, I. Tammen, and H. W. Raadsma. 2004. Quantitative trait loci mapping in dairy cattle: Review and meta-analysis . Genet. Sel. Evol. 36:163-190.

Laevens, H., H. Deluyker, Y. H. Schukken, L. De Meulemeester, R. Vandermeersch, E. De Muêlenaere, and A. De Kruif. 1997. Influence of parity and stage of lactation on the somatic cell count in bacteriologically negative dairy cows. J. Dairy Sci. 80:32193226

Lipkin, E., M. O. Mosig, A. Darvasi, E. Ezra, A. Shalom, A. Friedmann, and M. Soller. 1998. Quantitative trait locus mapping in dairy cattle by means of selective DNA pooling using milk samples and dinucleotide microsatellite markers: Analysis of milk protein percentage. Genetics 149:1557-1567.

Lipkin, E., T. Ruth, A. Friedmann, and M. Soller. 2008. Effect of quantitative trait loci for milk protein percent on milk protein yield and milk yield in Israel Holstein dairy cattle. J. Dairy Sci. 91:1614-1627

Mangin. B., B. Goffinet, and A. Rebaï. 1994. Constructing confidence intervals for QTL location. Genetics 138:1301-1308.

Manichaikul, A., J. Dupuis, S. Sen, and K. W. Broman. 2006. Poor performance of bootstrap confidence intervals for the location of a quantitative trait locus. Genetics 174:481-489.

Mosig, M. O., E. Lipkin, G. Khutoreskaya, E. Tchourzyna, M. Soller, and A. Friedmann. 2001. A whole genome scan for quantitative trait loci affecting milk protein percent in Israeli-Holstein cattle, by means of selective milk DNA pooling in a daughter design, using a modified false discovery rate criterion. Genetics 157:16831698

Ogorevc, J., T. Kunej, A. Razpet, and P. Dovc. 2009. Database of cattle candidate genes and genetic markers for milk production and mastitis. Anim. Genet. 40:832-851.

Pérez-Enciso, M., A. Clop, J. L. Noguera, C. Ovilo, A. Coll, J. M. Folch, D. Babot, J. Estany, M. A. Oliver, I. Díaz, and A. Sánchez. 2000. A QTL on pig chromosome 4 affects fatty acid metabolism:
Evidence from an Iberian by Landrace intercross. J. Anim. Sci 78:2525-2531.

Polineni, P. 2004. Developing a web accessible integrated database and visualization tool for bovine quantitative trait loci. MSc Thesis. Texas A\&M Univ., College Station,TX.

Rupp, R., and D. Boichard. 2003. Genetics of resistance to mastitis in dairy cattle. Vet. Res. 34:671-688.

Schepers, A. J., T. J. Lam, Y. H. Schukken, J. B. Wilmink, and W. J. Hanekamp. 1997. Estimation of variance components for somatic cell counts to determine thresholds for uninfected quarters. J. Dairy Sci. 80:1833-1840.

Schutz, M. M. 1994. Genetic evaluation of somatic cell scores for United States dairy cattle. J. Dairy Sci. 77:2113-2129.

Schweder, T., and E. Spjøtvoll. 1982. Plots of $P$-values to evaluate many tests simultaneously. Biometrika 69:493-502.

Seegers, H., C. Fourichon, and F. Beaudeau. 2003. Production effects related to mastitis and mastitis economics in dairy cattle herds. Vet. Res. 34:475-491.

USDA. 2008. Bovine genetic trends. http://aipl.arsusda.gov/eval/ summary/trend.cfm?R_Menu=HO.d\#StartBody.

Visscher, P. M., C. S. Haley, and R. Thompson. 1996. Marker-assisted introgression in backcross breeding programs. Genetics 144:19231932

Walsh, P. S., D. A. Metzger, and R. Higuchi. 1991. Chelex 100 as a medium for simple extraction of DNA for PCR-based typing from forensic material. Biotechniques 10:506-513.

Wang, J., K. J. Koehler, and J. C. Dekkers. 2007. Interval mapping of quantitative trait loci with selective DNA pooling data. Genet. Sel. Evol. 39:685-709.

Weller, J. I., and E. Ezra. 2004. Genetic analysis of the Israeli Holstein dairy cattle population for production and nonproduction traits with a multitrait animal model. J. Dairy Sci. 87:1519-1527.

Weller, J. I., Y. Kashi, and M. Soller. 1990. Power of daughter and granddaughter designs for determining linkage between marker loci and quantitative trait loci in dairy cattle. J. Dairy Sci. $73: 2525-2537$.

Zenger, K. R., M. S. Khatkar, J. A. Cavanagh, R. J. Hawken, and H. W. Raadsma. 2007. Genome-wide genetic diversity of Holstein Friesian cattle reveals new insights into Australian and global population variability, including impact of selection. Anim. Genet. 38:7-14.

\section{Appendix I. Details of Genotyping Procedures for Israel and Italy}

\section{Israel}

Aliquots of subpools and sire semen were prepared for PCR as described (Lipkin et al., 1998). The PCR reaction solution included $1 \times \mathrm{PCR}$ buffer, 0.5 to 8.75 $\mathrm{m} M \mathrm{MgCl}_{2}$ (depending on the amplification quality of each marker), $0.2 \mathrm{mM}$ deoxynucleotide triphosphate mixture, $10 \mu M$ of each forward primer labeled with fluorescent dye (FAM, HEX, TET, NED; Applied Biosystems, Foster City, CA), $2 \mathrm{U} / \mu \mathrm{L}$ of ABgene RH Taq polymerase (ABgene, Epsom, UK), and 2,000 lysed milk cells or 500 semen cells per reaction. Water was added to a final reaction volume of $10 \mu \mathrm{L}$. Amplification was performed in a MJ Research PTC-200 thermal cycler (GMI Inc., Ramsey, MN). Cycles included 1 step of $5 \mathrm{~min}$ at $95^{\circ} \mathrm{C} ; 35$ to 40 cycles of $1 \mathrm{~min}$ at $94^{\circ} \mathrm{C}, 1 \mathrm{~min}$ at 50 to $66^{\circ} \mathrm{C}$ according to the primer pair annealing temperature, and $30 \mathrm{~s}$ at $72^{\circ} \mathrm{C}$; and a final 
step of 8 or $90 \mathrm{~min}$ at $72^{\circ} \mathrm{C}$. The 90 -min final incubation was implemented when necessary to enable the Taq polymerase to add a final nontemplate base to all products to eliminate the half-step shadow bands that are occasionally obtained in a short incubation when a nontemplate base is added to some but not all products. The PCR products were diluted from 1:2 up to 1:150 according to PCR quality, and $1 \mu \mathrm{L}$ of the diluted PCR products was taken for analysis. Following the protocol provided by the DNA sequencing center of The Hebrew University (M. Korner, The Hebrew University of Jerusalem, Jerusalem, Israel; personal communication), the PCR products were mixed with formamide at $5 \times$ the standard ROX400, to a total volume of $12 \mu \mathrm{L}$. Of this mixture, $1 \mu \mathrm{L}$ was loaded on the capillaries and separated by electrophoresis on an ABI377 automatic sequencer (Applied Biosystems) using a 5\% acrylamide $0.2 \mathrm{~mm}$ gel.

\section{Italy}

Using an adapted procedure, DNA was extracted from aliquots of subpools with the QIAamp DNA Blood Midi Kit (Qiagen, Valencia, CA). Extracted pool DNA was resuspended in water to obtain DNA of approximately 2,000 cells $/ \mu \mathrm{L}$. Sire's semen DNA was extracted using a Chelex protocol (Walsh et al., 1991). The PCR analyses of pool and semen DNA were carried out in a $10-\mu \mathrm{L}$ reaction volume that included 1 to $2 \mu \mathrm{L}$ of DNA template, $2 \mathrm{pmol}$ of labeled forward primer (dyes were 6-FAM, HEX, and TET; Eurofins MWG Operon, Ebersberg, Germany), 2 pmol of unlabelled primer, $2.5 \mathrm{mM}$ deoxynucleotide triphosphate mixture, 1.5 to $3.5 \mathrm{mM}$ $\mathrm{MgCl}_{2}$, and $0.5 \mathrm{U}$ of Taq DNA polymerase (EuroTaq, EuroClone, Siziano, Italy). Analyses were carried out using PerkinElmer 9600 (PerkinElmer, Waltham, MA) or MJ Research PTC100 (GMI Inc.) thermal cyclers with the following temperature and cycling profile: a first denaturation step of 8 min at $95^{\circ} \mathrm{C} ; 30$ cycles of 1 min at $95^{\circ} \mathrm{C}, 1 \mathrm{~min}$ at a specific annealing temperature for each microsatellite marker, and $1 \mathrm{~min}$ at $72^{\circ} \mathrm{C}$; and a final extension of $60 \mathrm{~min}$ at $72^{\circ} \mathrm{C}$. The PCR products (0.5 to $1.0 \mu \mathrm{L}$ of reaction product) were diluted in 10 $\mu \mathrm{L}$ of Hi-Di formamide (Applied Biosystems) and added to $0.1 \mu \mathrm{L}$ of Rox labeled DNA ladders (500HD Rox, Applied Biosystems). The prepared samples were electrophoresed on an ABI3100 Avant capillary sequencer (Applied Biosystems).

\section{Appendix II. Statistical Details of the MMM Procedure}

As in SMM, MMM starts with the observed $\mathrm{Z}_{\mathrm{ij}}^{2}$ test statistics obtained for those markers for which a sire is heterozygous and tested. Given a $\mathrm{Z}_{\mathrm{ij}}{ }^{2}$ test statistic for a marker at a known chromosomal location, the predicted MMM test statistic at a marker not tested in the sire, located at a given distance away from an observed SMM test statistic, depends on the recombination rate between these 2 loci. In particular, the MMM test statistic at any location on the chromosome is calculated as $\mathrm{E}\left(\mathrm{T}_{1}\right)=\mathbf{b}^{\prime} \mathbf{t}$, where $\mathbf{t}$ is a vector of all observed SMM test statistics $\left(\mathrm{T}_{\mathrm{i}}\right)$, with $\mathbf{V}=\operatorname{var}(\mathbf{t})$, the variance-covariance matrix of $\mathbf{t}$, and $\mathbf{b}$ the solution vector of $\mathbf{V}^{-1} \mathbf{c}$, with $\mathbf{c}$ being a vector of covariances between predicted $\left(\mathrm{T}_{1}\right)$ and observed $\left(\mathrm{T}_{\mathrm{i}}\right)$ test statistics. In this way, each chromosomal marker in a sire has an associated test statistic, obtained directly as $\mathrm{Z}_{\mathrm{ij}}{ }^{2}$ for markers heterozygous and tested in the sire, or indirectly as the MMM estimate for markers that were not tested in the sire and any other position on the chromosome. For calculation of $P$-values, the df at each marker along the chromosome were calculated as the proportion of variance explained by the markers, namely, $\operatorname{df}(\mathrm{MMM})=\left(\mathbf{b}^{\prime} \mathbf{V b}\right) / \operatorname{var}(\mathbf{t})$ (Visscher et al., 1996) and summed across sires. The number of marker tests reaching some predetermined critical CWER $P$ value under MMM will depend, therefore, on the balance between the increase in the MMM test statistic and the increase in the MMM df, and needs not always result in greater statistical significance for the MMM relative to SMM. 